\title{
The Impact of Inclusive Education on Learners with Disabilities in High Schools of Harare, Zimbabwe
}

\author{
Tinashe Chuchu1 ${ }^{*}$, Vimbai Chuchu² \\ ${ }^{1}$ University of the Witwatersrand, South Africa \\ ${ }^{2}$ Womens' University in Africa, Zimbabwe \\ *tinashe.chuchu@wits.ac.za
}

\begin{abstract}
The problem of low inclusive education is essential to research as it highlights the importance of equal opportunity to all students regardless of mental or physical ability. The study was conducted within a Zimbabwean high school context. The purpose of the study was to conduct an empirical investigation into the impact of inclusive education and therefore establish the extent to which it has benefited students with disabilities in four high schools in the Harare province. Furthermore, study's intention was to therefore propose a theoretical framework that could be used to address low success in inclusive education. The methodology was qualitative in nature and interviews were used to collect research data. Quota sampling was adopted in selection of suitable respondents. It was observed that a lack of financial and human resources, as well as effective policies had contributed to the low impact of inclusive education in high schools in Harare, Zimbabwe. In conclusion the results also revealed that inclusive education in high schools in Harare had not made much of an impact due to negative perceptions and attitudes of the people that are pivotal to its success.
\end{abstract}

Keywords: Inclusive, education, disability, high schools

\section{Introduction}

Inclusive education has received much attention globally and is viewed as a major challenge for educational systems across the world (Florian \& Linklater, 2010; Srivastava, de Boer \& Pijl, 2015; Baldiris-Navarro, Zervas, Fabregat-Gesa \& Sampson, 2016). The current research aims to review relevant literature that explores inclusive education with special focus on learners with disabilities whilst identifying trends in literature. It has been noted in past literature (Ainscow, 2005) that inclusion is a major challenge that educational systems the world over experience. Ainscow (2005)goes on further to state that the main problem to successful inclusive strategies in education require a change in the existing way of thinking which has been detrimental to progress in inclusiveness in schools. The present study makes an extension to Ainscow (2005) by proposing a framework that would help in altering existing perceptions towards inclusive education and provide a new way of viewing inclusive education in schools.

Motivation and purpose of the study: The present study is motivated by the need to understand how inclusive education has been implemented in Harare highs and whether it has been beneficial to the learners with disabilities themselves. The study aims to ascertain the impact that the advent of inclusive education has on learners with disabilities in high schools. It is therefore imperative to establish if there is inclusion after all in those schools. If so is the impact negative or positive? In ascertaining the impact the institutions and communities may be able to improve on. The study is of significance and relevance to a large number of entities, some of these include the following: academia, school authorities, learners, researchers and government as all these players are central to the success of inclusive education in schools. The remainder of this paper will comprise of the review of relevant literature, methodology, results and discussion, conclusion, recommendations, acknowledgements and lastly a list of references.

Inclusive education is a global phenomenon that arose as a response to the exclusion of students who were viewed as different in terms of colour, socioeconomic background or being disabled (Waitoller \& Artiles, 2013).Inclusive education also seeks to ensure that learners with varied needs and preferences (such as learners with disabilities) are provided equal opportunities in accessing learning resources, services and experiences (Florian \& Linklater, 2010; Baldiris-Navarro et al., 2016). Waitoller \& Artiles (2013) assert that a 
serious imperative for the development of inclusive school systems is the capacity to nurture and develop teachers who have the comprehension, skills, critical sensibilities, and contextual awareness to provide quality educational access, participation and outcomes for all learners. Furthermore Waitoller \& Artiles (2013) state that research on teacher learning for inclusive education emphasises what researchers view as a measure of change in the process of becoming inclusive teachers and schools. Disabilities are broken down into several categories namely: learning disabilities, mental challenges, visual impairments, hearing impairment, speech and language disorders, physical and motor disabilities, emotional and behavioural disorders and lastly health related disorders, as cited by (Chimonyo, Kaputa, Mamvura, Hlatywayo, Munemo \& Nyatsanza, 2011). The international community has considered the education of students with special needs to be of great importance ever since the 1994 United Nations Salamanca statement and framework for action on special needs education (Arrah \& Swain, 2014). According to Arrah \& Swain (2014) students with special needs have not received education in general education settings historically. The main aim and goal for this article is to review relevant literature on inclusive education focusing on leaners with disability as well as exploring trends in the field of study.

Inclusive and child-conducive education should therefore be seen as an approach to school development as it is about making quality education available to all (Harris, Miske \& Attig, 2004). According to Harris et al. (2004) the majority of children with disabilities in developing countries are not enrolled in school. This finding is shared by Ainscow (2005) who states that most of the children from less economically developed countries never get a chance to even see the inside of a classroom. Inclusive education, considered as a practice of providing all learners with equal educational opportunities, is a major challenge for many educational systems worldwide. Baldiris-Navarro et al. (2016) posit that in order to address this issue, a broadly used framework known as the Universal Design for Learning (UDL) can be adopted to provide specific educational design guidelines that ensure accessibility of all learner types to the learning environment. Persons with disabilities were conventionally perceived as dependent individuals who evoke sympathy, if not pity and require societal security and support to compensate for their inabilities (Hendricks, 2007). As such, they were predominantly viewed as objects of care instead of legal subjects entitled to dignity and the full privilege of human rights (Hendricks, 2007). The following section outlines some key aspects of the present paper which are as follows: the gap in research, problem statement, research questions, objectives and the justification of the study. The section will also highlight what is known about research in the area of inclusive education and what needs to be known therefore leading to the research problem.

Gap in research: Inclusive education as a research area has received at great deal of attention from researchers such as (Ainscow, 2005; Mittler, 2012).Research conducted by (Ainscow, 2005) explored inclusive education in the context of different economic classes while (Mittler, 2012) researched inclusive education very broadly in that there was discussion many aspects of inclusive education such as human rights, disabilities and parents' role in the student's education. The two authors (Ainscow, 2005; Mittler, 2012) had contradicting views were by (Ainscow, 2005) stated it was imperative for change in existing thought towards inclusive education however (Mittler, 2012) argues that a change was not necessary. Both authors (Ainscow, 2005; Mittler, 2012) investigated inclusive education at great depth but did not cover much on how learners' with disability in particular were affected by inclusive education policies more specifically in high school settings. This research therefore identifies a gap of trying to incorporate both opposing views the and mainly focusing on the disability aspect of inclusive education.

Problem Statement: Despite the advent of inclusive education learners with disabilities still face attitudinal, structural and physical barriers in accessing quality education. The research question that the present study seeks to address concerns establishing the extent to which inclusive education has made an impact in high schools of Harare, Zimbabwe? Objectives of the study are to assess how disabilities and inclusion are perceived by teachers and heads of the schools as well as to establish if learners with disabilities have benefit from inclusive educational practices. 


\section{Literature Review}

Baker (2000) considers reviewing current literature relevant to a research topic to be an essential first step and foundation for undertaking the research project. Therefore review of literature plays a crucial role in the current research. In the sections to follow efforts will be directed towards exploring the findings of other studies conducted by various scholars in the same field.

Theoretical Grounding: Particular attention will be paid to the following theories: the concept of inclusion, self-efficacy theory and the philosophy of normalisation.

The concept of Inclusion: The concept of inclusion was deemed necessary for the present study as this study is grounded on inclusiveness. Salend (2001:5) defines inclusion as an attempt to "establish collaborative, supportive, and nurturing communities of learners that are based on giving all students the services and accommodations they need to learn, as well as respecting and learning from each other's individual differences."Mittler (2012) states that concept of inclusion involves a radical re-think of practise and policy thereby introducing a fundamentally new perception of the origins of learning and behavioural difficulties. Prior literature has supported inclusive education (Jobe, Rust \& Brissie, 1996 and Malian \& Love, 1998) who established that inclusive programs have a more positive impact on providing academic support to students with mild disabilities when compared to segregated settings. However the concept of inclusion has been criticised as well in past literature (Mastropieri \& Scruggs, 2000; Salend, 2001) suggesting that inclusion has been associated with inadequate training of general education teachers to work with students with disabilities.

Self-efficacy theory: The self-efficacy theory was also considered to be of relevance to the study at hand as it was used in an attempt to understand learners with disabilities. The Self-efficacy concept, according to theorist Bandura (1997), can be defined as a belief in one's ability to succeed in specific situations. An individual's sense of self-efficacy can be an influential factor in how the person approaches goals, tasks, and challenges as their confidence in their own ability to behave in a way that allows control of the events which influence their life. Self-efficacy belief represents the basis of human agency. If trust in succeeding in something is little, therefore the weaker is the stimulus to do something (Bandura, 1997). Self-efficacy is a part of the self-concept and develops in the process of individualization. Understanding the process of individualization and formation of self-concept enables one to recognize the process of development of stress resistance as a component of the self-concept. The development of self-efficacy is closely connected to the process of socialisation and it interacts with it more essentially than other aspects of the arising personality. People gain a conviction of their self-efficacy from experience, social modelling, social persuasion in efficacy and reduction of stress or depression according to (Bandura, 1997).

Philosophy of normalisation: The concept of normalisation refers to optimising conditions for normal living and including persons with disabilities (Meyer, 2003). According to Meyer (2003) the concept of normalisation was given a systematic and theoretical description by (Nirje, 1969).Normalisation can also be described as a sociological theory of the implementation, embedding and integration of new technologies and organisational innovation according to (May, Mair, Dowrick \& Finch, 2007).This theory explains that when people are segregated labelled or treated in any way that is different, then their worth is devalued, as purported by (Winant, 1997). This theory becomes paramount to the current study as it aids the comprehension of including others in society.

Perceptions on Disability and Inclusion: Hanson, Horn, Sandall, Beckman, Morgan, Marquart \& Chou (2001)carried out a research to determine parent's perspective of their children's school experiences .This was in order to identify those factors that influenced inclusive placement decisions. Most of the parents valued inclusive placement, concerns about class size, availability of therapeutic services, acceptance by other children, attitudes about the child' $s$ disability, as well as teachers' level of training and experience were expressed. The parent's views' along with those of teachers and therapists were also garnered to examine the environmental influences of children's social experiences in school (Baker \& Donnelly 2001). Even though only one of the four children with Fragile X syndrome attended a fully inclusive class, the authors (Baker \& Donnelly 2001) stress the importance of the school environment for influencing the quality of social experiences, specifically, its physical environment, other children, executive staff, professionals and policy. 
The issues noted from these studies describe barriers to inclusive education and emphasises the value of parental reports for assessing and evaluating inclusive school environments and practices.

Views of Learners with Disabilities: Ronen, Rosenbaum \& Streiner (1999) asset that students are fully capable of identifying, expressing accessibility concerns therefore should be allowed opportunity to participate in evaluating inclusive environments. Ronen et al. (1999) also carried out a study on youth with epilepsy to provide their perceptions of the condition in order to identify health-related quality of life factors.

School Records Reflections Regarding Learners with Disabilities: According to (Carter, 2007) peers play an important role in successful implementation of inclusive education in schools. Even though students need interactions with peers, they often do not occur naturally for various reasons (Lillie \& Vakil, 2002). However, peer related interactions seem to reduce the number of necessary interactions with adults and support deeper involvement in instructional and class-room practices of students with disabilities (Lillie \& Vakil, 2002). Reducing children's dependency on adults make them more involved within their class (Carter, 2007).

\section{Methodology}

As far as procedural design was concerned participants were approached at their schools where they were informed about the study and its purpose. The study adopted a qualitative approach to collecting research data. Interviews were conducted with school heads and teachers of the respective schools. Finally with regards to the qualitative approach the researcher made observations of the students at the schools that took part in the study.

Study Area and Target population Description: The target population comprised of 24 teachers (6 from each school), and 4 school heads(1 representing each school)from the following high schools; Danhiko High School, Prince Edward, High School Roosevelt High School and Dzivarasekwa 2 High all in Harare. This sample was considered to be fair representation of the population as all participating schools were equally represented.

Sampling Method and Size: Quota sampling was adopted in selection of suitable respondents. This sampling method was deemed most appropriate as it ensured that a certain characteristic of the population sample will be represented to the exact extent that the researcher requires as stated by (Acharya, Prakash, Saxena \& Nigam, 2013). These subjects were selected through stratifying them by age, sex and length of time in service.

\section{Results and Discussion}

Sample Description: Table 1 illustrated in the following section presents a profile of the teachers who participated in the study.

Table 1: Teachers' Demographic Profile

\begin{tabular}{lll}
\multicolumn{1}{l}{ Variable } & Frequency & Percentage \\
\hline $21-30$ & & \\
$30-40$ & 4 & $16,7 \%$ \\
$41-50$ & 7 & $29,10 \%$ \\
$50+$ & 10 & $41,7 \%$ \\
Total & 3 & $12,5 \%$ \\
& 24 & $100 \%$ \\
Sex & & \\
Female & Frequency & Percentage \\
Male & 14 & $58,3 \%$ \\
Total & 10 & $41,7 \%$ \\
& 24 & $100 \%$ \\
Length of time in service & & \\
$0-5$ & Frequency & Percentage \\
\hline
\end{tabular}




\begin{tabular}{lll}
\hline $6-15$ & 7 & $29,10 \%$ \\
$15-25$ & 10 & $41,7 \%$ \\
$30+$ & 3 & $12,5 \%$ \\
Total & 24 & $100 \%$ \\
\hline
\end{tabular}

Table 1 above illustrates the demographic results of the study. Of the 24 teachers that filled out questionnaires given out by researcher, $10,(41.7 \%)$ fell in the $41-50$ age range and have been in the service for over 15 years, as data indicates in the diagram below. This group had the largest representation. What was noted by the researchers, which was striking, was that those who fell in this age range responded in a similar pattern to the question pertaining to their views on inclusive education. Their responses were in agreement with the statement 'inclusive education is idealistic and not beneficial to learners, with disabilities.' Teachers play an integral to the success of effective inclusion in the school, hence their perceptions and attitudes concerning it; have got to be highly positive. This statistic has a bearing on the future of inclusive education, because this generation of teachers most likely constitutes the majority of teachers in the country, who have just the right experience to contribute meaningfully to this concept and are not close to retirement, for the sake of mentorship and continuation. Another $3(12,5 \%)$ concurred with the above statement, the remaining 11 $(45,8 \%)$, strongly disagreed that inclusive education was just an ideal.

Figure 1: Illustration of Learners with Disabilities per School

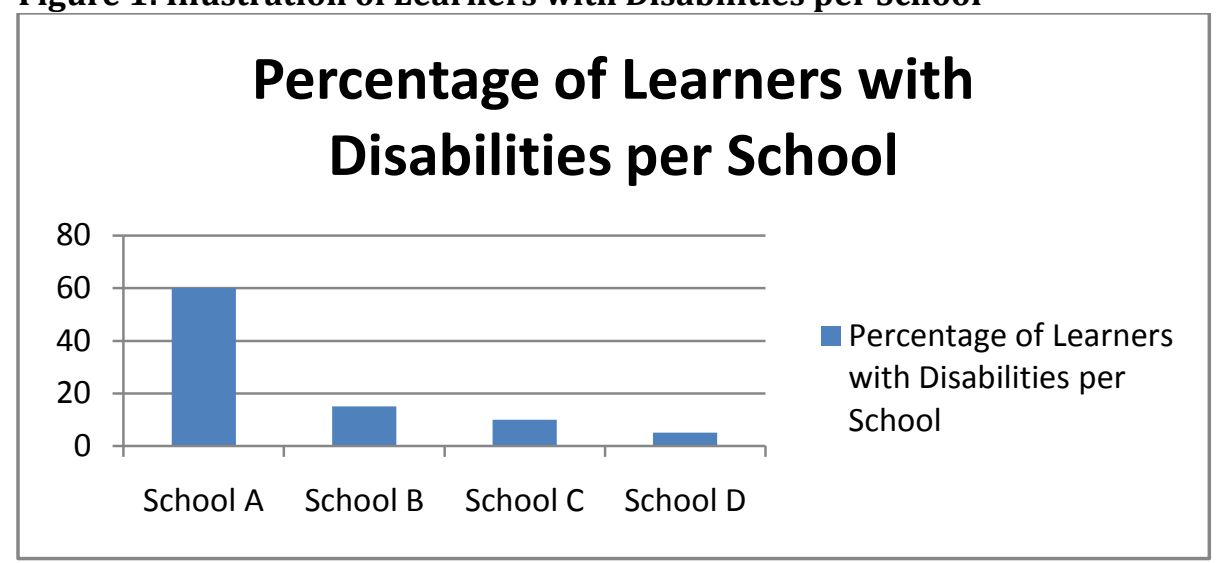

Figure 1 illustrates the percentage of learners with disabilities. School A had the highest number of leaners with disabilities as indicated by $60 \%$ of the total learners of that school. This was followed by School B represented by 15\%, School C represented by $10 \%$ and finally School D had the lowest representation indicated by $5 \%$ of the total learners of that school. Table 2 below shows an illustration of responses from heads of schools regards school policies concerning inclusion.

Table 2: School Policies with Regards to Inclusion

\begin{tabular}{ll}
\hline School Heads & Responses \\
\hline A & $\begin{array}{l}\text { Yes, there is policy in place which states that every child must be afforded equal } \\
\text { opportunities regardless of creed, disability or social status. The policy is very well } \\
\text { implemented. }\end{array}$ \\
B & $\begin{array}{l}\text { Yes, there is policy in place, which consists of a full code of conduct document on how } \\
\text { to accommodate learners with disabilities. There are challenges here and there on }\end{array}$ \\
& implementation, but we try. \\
T & $\begin{array}{l}\text { There is no particular policy, nothing formal in place as such, but learners and } \\
\text { teachers are always encouraged to treat everyone without discrimination. }\end{array}$ \\
There is no policy in place but it is a non-discriminatory school, however we do not \\
have adequate resources for total inclusion
\end{tabular}

On the following page table 3 illustrates school policy views and it can be observed that all $9(100 \%)$ teachers, agreed that the policy was well implemented and that it encouraged the enrolment of learners with 
disabilities. When it came to the allocation of budgets $4(44,4 \%)$ agreed there were adequate funds directed towards the promotion of inclusive education, $5(55,6 \%)$ disagreed with this notion. This is a clear indication that inclusive education in schools is currently not a priority, as the allocated funds, towards its promotion are showing to be inadequate. In addition, $7(77,7 \%)$ of these teachers agreed that the policies clearly outlined the duties of the teachers, administrators and school authorities. The remaining $2(22,3 \%)$ disagreed with the above notion. It is of paramount importance that teachers know their roles in inclusive settings. This will have an influence on the impact of inclusive education.

Regarding training, the teachers were asked to indicate whether they had ever received any training on how to work with learners who have special needs. 8 teachers $(33,3 \%)$ indicated 'yes' they had received special training in working with children. The other $16(66,7 \%)$ indicated 'no' they had not received any special training, in that area. Scarce teachers with training in this area can be a hindrance to the successful implementation of an inclusive education, let alone impactful implementation. This is an indication that right from the teacher training colleges they roll out few specialists in 'special needs education'. Schools in the same vein to not carry out in-house training, workshops or seminars to equip teachers on how to include learners with special needs in the mainstream schools, to equip teachers. Illustrated on the following page is table 4 highlighting heads of schools responses' to academic, sporting and social clubs' performance questions.

Table 3: Illustration of School Policy Views

\begin{tabular}{|c|c|c|}
\hline Variable & Frequency & Percentage \\
\hline \multicolumn{3}{|l|}{ Views on the policy } \\
\hline Policy is well implemented & 9 & $100 \%$ \\
\hline Agree & 0 & $0 \%$ \\
\hline \multicolumn{3}{|l|}{ Disagree } \\
\hline Total & 10 & $100 \%$ \\
\hline \multirow{2}{*}{$\begin{array}{l}\text { It encourages enrolment of learners with } \\
\text { disabilities }\end{array}$} & 9 & 100 \\
\hline & 0 & 0 \\
\hline \multicolumn{3}{|l|}{ Agree } \\
\hline \multicolumn{3}{|l|}{ Disagree } \\
\hline Total & 10 & $100 \%$ \\
\hline Has adequate budget allocation & 4 & 44,4 \\
\hline Agree & 5 & 55,6 \\
\hline \multicolumn{3}{|l|}{ Disagree } \\
\hline Total & 10 & $100 \%$ \\
\hline Clearly outlines roles of teachers, administrators & 7 & 77,7 \\
\hline and school authorities & 2 & 22,3 \\
\hline \multicolumn{3}{|l|}{ Agree } \\
\hline Disagree & & \\
\hline
\end{tabular}

Table 4: Heads' Responses to Academic, Sporting and Social Clubs' Performance Questions

\begin{tabular}{ll}
\hline Respondents: School Heads & Responses \\
\hline A & Academic performance: Below expected average. \\
& Sporting Activities: Depends on sport and facilities, there is very \\
& little or no participation at all. \\
& Participation in social clubs: little or no participation. \\
& Academic performance: Their performance is worse than those of \\
& able bodied learners. \\
& Sporting Activities: They perform very well at the special sports and \\
& win gold and silver for the school. \\
& Participation in social clubs: They take part actively and recently \\
& they took part in starbrite competitions in which they did very well. \\
& Academic performance: Their performance is just as good as any \\
&
\end{tabular}


other learner who is in the same environment.

Sporting Activities: There is need to encourage them to participate fully in sports. Successes were recorded in golf.

Participation in social clubs: They have been involved in activities such as drama, debate and junior council activities.

D

Academic performance: Depends on disability, some perform quite well and others are affected by their disability negatively, possibly feel less confident in their approach.

Sporting Activities: Participation is heavily compromised as there are no proper facilities for the disabled.

Participation in social clubs: They feel they don't fit in normal clubs, they consider them anti-social as their needs are not catered for.

After analysis of research data, a conceptual framework was developed. Below is an illustration of the research conceptual framework.

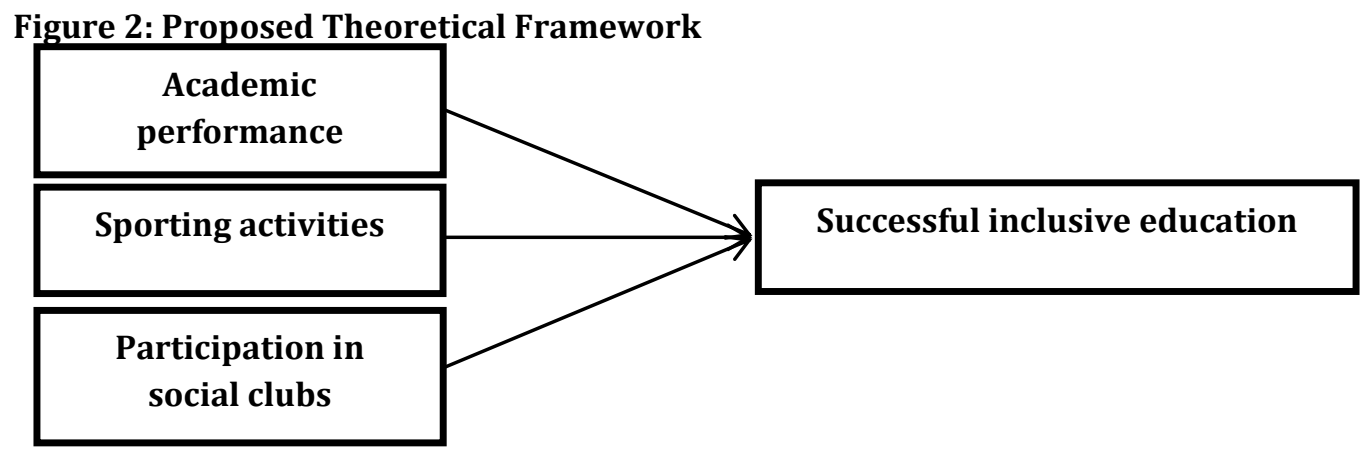

Source: Compiled by researcher (2016)

Based on the findings of the study as indicated in table 4 a theoretical framework was proposed (figure2). As illustrated in figure 2 above it is proposed that academic performance, sporting activities and participation in social clubs are key factors that could be used to assess whether inclusive education has been successful in schools as all three variables provided useful insights on the study of inclusive education and particularly more so for the present research.

\section{Conclusion}

The contribution of this study was to determine how inclusive education can be implemented effectively in high schools, with everyone on board, making their contribution towards the creation of supportive schools and communities. Based on the findings of this study the researcher was able to draw conclusions on the perceptions that of school heads and teachers have about inclusive education. Implications for schools authorities are that more attention to learners with special needs is necessary through constantly improving their approach to providing the best possible support and adapting best practices that have been successful in other countries to the Zimbabwean high school set up.The general theme that the research took away from school heads as far as academic performance of disabled students was concerned is that they performed significantly lower than their able bodied counterparts.

Recommendations: The present study provides some implications for researchers and educators in the realm of inclusive education. Based on the findings of the study the implication for researchers are that not enough research has been conducted as far as addressing the issue of inclusive education referring to learners with disabilities since there are still gaps in literature and unresolved problems that hinder successful implementation of inclusive education practises that are meant to benefit those learners with disabilities. The practical implication of the present study also based on the results is that educators are to become more engaged in academic, sporting and social activities more with learners that have disabilities in order to archive overall success in implementation of inclusive education practices and the current approach 
benefited those students to a lesser extent. It is also therefore recommended for teachers to conduct workshops with disabled students, on special needs education, thus facilitating effective implementation of inclusive education. It is further recommended that for inclusive education to take effect behavioural change could be necessary amongst the concerned stakeholders like the school heads, teachers, students and parents. The author recommends that the government ministries responsible for education at all levels and that of sports, arts and cultures allocate specific funds and other resources towards making schools more inclusive as well as put in place more effective policies that address low success in inclusive education. Other recommendations for future research involve considering the role that can be played by communities were learners with disabilities reside and see if there is a correlation with their social and academic performance at school. Similar research as to the present one can be done using a larger sample from a greater geographic area such as a province or from more than just one city as the approach adopted for the present study could have compromised the findings.Raising awareness on disability issues could be beneficial for schools and communities at large, thus eliminating the element of discrimination and stigma attached to disability. Lastly the researcher recommends that until stakeholder perceptions in schools become more positive and further developments undertaken by responsible authorities to improve the state of schools to ensure policies in place are well implemented inclusive education would not benefit disabled students much.

Theoretical Contribution of the Study: Based on finds of the study key themes were observed and these were the lack of appreciation of inclusive education in the high school education system as indicated by inadequate support that students with disabilities received. The study further contributes to literature through establishing that acknowledgement of students' disability alone is not sufficient as the students remained significantly disadvantaged as compared to their able-bodied counterparts. This promoted an extension to existing literature in the form of a proposed theoretical framework provided in figure 2 . The present study however leaves room for potentially interesting future research through conducting an empirical study on how inclusive education is perceived by the students themselves considering that the present study assessed inclusive education from the perspective of the teachers and school heads.

Acknowledgements: The author would wish to thank the heads, staff and students of Danhiko High School, Prince Edward High School, Roosevelt High School and Dzivarasekwa 2 High School as well as the Harare School District (that provided access to participants) for participating in the study.

\section{References}

Acharya, A. S., Prakash, A., Saxena, P. \& Nigam, A. (2013). Sampling: Why and how of it. Indian Journal of Medical Specialties, 4(2), 330-333.

Ainscow, M. (2005). Developing inclusive education systems: what are the levers for change? Journal of educational change, 6(2), 109-124.

Arrah, R. 0. \& Swain, K. D. (2014). Teachers' Perceptions of Students with Special Education Needs in Cameroon Secondary Schools. International Journal of Special Education, 29(3), 101-110.

Baker, K. \& Donelly, M. (2001). The social experiences of children with disability and the influence of environment: A framework for intervention. Disability \& Society, 16(1), 71-85.

Baker, M. J. (2000). Writing a literature review. The Marketing Review, 1(2), 219-247.

Baldiris-Navarro, S., Zervas, P., Fabregat-Gesa, R. \& Sampson, D. G. (2016). Developing Teachers' Competences for Designing Inclusive Learning Experiences. Journal of Educational Technology \& Society, 19(1), 17 27

Bandura, A. (1997). Self-efficacy: The exercise of control. (1sted) N Y: W H Freeman and Company Carter, E. W. (2007). Including people with disabilities in faith communities: A guide for service providers, families, \& congregations. IL. Paul H Brookes Publishing Company.

Chimonyo, I., Kaputa, T. M., Mamvura, E. K., Hlatywayo, L., Munemo, E. T., Nyatsanza, T. D., Mutandwa, E. (2011). Breaking down Barriers to Inclusive Education in Zimbabwe: A teachers Handbook, Zimbabwe Open University, Harare

Florian, L. \& Linklater, H. (2010). Preparing teachers for inclusive education: using inclusive pedagogy to enhance teaching and learning for all. Cambridge Journal of Education, 40(4), 369-386 
Hanson, M. J., Horn, E., Sandall, S., Beckman, P., Morgan, M., Marquart, J. \& Chou, H. Y. (2001). After preschool inclusion: Children's educational pathways over the early school years. Exceptional children, 68(1), 65-83.

Harris, R., Miske, S. \& Attig, G. (2004). Embracing Diversity: Toolkit for Creating Inclusive Learning-Friendly Environments. UNESCO Bangkok.

Hendricks, A. (2007). UN Convention on the Rights of Persons with Disabilities. Eur. J. Health L., 14, 273.

Jobe, D., Rust, J. O. \& Brissie, J. (1996).Teachers attitudes toward inclusion of students with disabilities into regular classrooms. Education, 117(1), 148.

Kuen-Fung, S. (2013). The practice and critical issues on inclusive education in Hong Kong. 6th changpa Cangbo. haksulje International, 17-27.

Lillie, T. \& Vakil, S. (2002). Transitions in early childhood for students with disabilities: Law and best practice. Early Childhood Education Journal, 30(1), 53-58.

Malian, I. M. \& Love, L. L. (1998). Leaving high school: An ongoing transition study. Teaching Exceptional Children, 30(3), 4.

Mastropieri, M. A. \& Scruggs, T. E. (2000). The inclusive classroom: Strategies for effective instruction. New Jersey: Merrill.

May, C. R., Mair, F. S., Dowrick, C. F. \& Finch, T. L. (2007). Process evaluation for complex interventions in primary care: understanding trials using the normalization process model. BMC Family Practice, 8(1), 1.

Meyer, J. (2003). A non-institutional society for people with developmental disability in Norway. Journal of Intellectual and Developmental Disability, 28(3), 305-308.

Mittler, P. (2012). Working towards inclusive education: Social contexts. New York. USA. Routledge.

Nirje, B. (1969). A Scandinavian visitor looks at US institutions. Changing patterns in residential services for the mentally retarded, 51(54).

Ronen, G. M., Rosenbaum, P., Law, M. \& Streiner, D. L. (1999). Health-related quality of life in childhood epilepsy: the results of children's participation in identifying the components. Developmental Medicine \& Child Neurology, 41(8), 554-559.

Salend, S. J. (2001). Creating inclusive classrooms: Effective and reflective practices New Jersey: Merrill.

Srivastava, M., de Boer, A. \& Pijl, S. J. (2015). Inclusive education in developing countries: a closer look at its implementation in the last 10 years. Educational Review, 67(2), 179-195.

Waitoller, F. R. \& Artiles, A. J. (2013). A decade of professional development research for inclusive education a critical review and notes for a research program. Review of educational research, 83(3), 319-356.

Winant, H. (1997). Where culture meets structure. Race, class, and gender in a diverse society, ed. Diana Kendall, 27-38. 